\title{
Investigation on the Microstructures and \\ Mechanical Properties of Friction Stir Processed 2A14 Aluminum Alloy Fabricated by Different Initial Precipitation States
}

\section{Jian Wang ( $\nabla$ wjhij1217@163.com )}

Hohai University - Changzhou Campus

\section{Ke Yang}

College of Mechanical and Electrical Engineering, Hohai University, Changzhou 213022, China

\section{Dongshuai Zhou}

Key Laboratory of Advanced Materials Design and Additive Manufacturing of Jiangsu Province, Changzhou 213001, China.

\section{Li Xie}

School of Materials Engineering, Jiangsu University of Technology, Changzhou 213001, China;

\section{Yalin Lu}

Key Laboratory of Advanced Materials Design and Additive Manufacturing of Jiangsu Province, Changzhou 213001, China.

\section{Xingcheng Li}

Key Laboratory of Advanced Materials Design and Additive Manufacturing of Jiangsu Province, Changzhou 213001, China.

\section{Research Article}

Keywords: 2A14 aluminum alloy, Friction stir processing, Initial precipitation state, Microstructural evolution, Mechanical properties

Posted Date: March 1st, 2021

DOl: https://doi.org/10.21203/rs.3.rs-243089/v1

License: (c) (i) This work is licensed under a Creative Commons Attribution 4.0 International License. Read Full License

Version of Record: A version of this preprint was published at The International Journal of Advanced Manufacturing Technology on July 21st, 2021. See the published version at 
https://doi.org/10.1007/s00170-021-07709-9. 


\title{
Investigation on the microstructures and mechanical properties of
}

\section{friction stir processed $2 \mathrm{~A} 14$ aluminum alloy fabricated by different}

\author{
initial precipitation states \\ Jian Wang a,b ${ }^{\text {a }}$ Ke Yang a , Dongshuai Zhou ${ }^{\mathrm{c}}$, Li Xie ${ }^{\mathrm{b}}$, Yalin $\mathrm{Lu}^{\mathrm{b}, \mathrm{c}^{*}}$, Xingcheng $\mathrm{Li}^{\mathrm{c}}{ }^{\text {* }}$ \\ ${ }^{a}$ College of Mechanical and Electrical Engineering, Hohai University, Changzhou 213022, China; \\ ${ }^{\mathrm{b}}$ School of Materials Engineering, Jiangsu University of Technology, Changzhou 213001, China; \\ ${ }^{\mathrm{c}}$ Key Laboratory of Advanced Materials Design and Additive Manufacturing of Jiangsu Province, \\ Changzhou 213001, China.
}

Abstract: $6 \mathrm{~mm}$ thick 2A14 Al alloy plates were friction stir processed with different initial precipitation states of as-cast, homogenization, rolling and T6. The results indicated that FSP can dramatically reduce the grain and particles size and promote the formation of fine recrystallized grains with random orientation in the stirred zone (SZ). No significant influences of the initial precipitation states of base metal (BM) on the grain size, grain boundary characteristic, texture component and texture intensity of SZ were perceived. Rather, the initial precipitation states can evidently affect the morphology and distribution of precipitates and dislocations. The dominant $\mathrm{C}$ and $\mathrm{A}_{1}$ * texture components developed in the SZ are correlated with the shear deformation and dynamic recrystallization. And the weakened texture intensity created in the SZ after FSP also signifying that discontinuous dynamic recrystallization might be involved. Compared with the corresponding $\mathrm{BM}$, the $\mathrm{SZ}$ fabricated by the $\mathrm{BM}$ under as-cast and homogenized states were strengthened arises from the obvious refined grains, uniform dispersed particles and elimination of casting defects caused by FSP, while the softening of SZ were observed for the BM under rolled and T6 states, which are mainly dependent on the reduction of dislocation density and dissolution/coarsening of fine precipitates during FSP.

Keywords: 2A14 aluminum alloy; Friction stir processing; Initial precipitation state; Microstructural evolution; Mechanical properties

* Corresponding author. E-mail: luyalin@163.com; sgylxc@jsut.edu.cn Tel.: +86-0519-8965-3281; Fax: +86-0519-8965-3281 


\section{Highlights}

- Microstructural evolutions were investigated by SEM, EDS, TEM and EBSD.

- FSP can generate the change of grain structure, grain boundary character distribution, microtexture, dislocation density and dispersions for the BM under different initial precipitation states.

- The changes of mechanical properties were evaluated.

\section{Introduction}

The 2A14 aluminum alloy has potential for various high performance applications in the aerospace structural components, transport systems and defense equipment because of its high strength to weight ratio, excellent fracture toughness and corrosion resistance $[1,2]$. Friction stir processing (FSP) is a local thermo-mechanical metal processing technology that was developed from the revolutionary material joining method of friction stir welding (FSW) [3]. As a large plastic forming process, FSP provides an extensive prospect for refining the grain of aluminum alloys, which can in turn contribute to the enhancement of mechanical properties and other properties [4, 5]. It has been also proposed as a potential solid-state processing technique to modify microstructures, achieve superplasticity, and synthesize in-situ composites and intermetallic compounds [6, 7].

In recent years, several scholars have investigated extensively the effect of processing parameters of FSP on the microstructures and properties of SZ [8-11]. Feng et al. [7] surveyed the FSP of 2219 aluminum alloy with different spindle rotation speeds. They proclaimed that the hardness values of SZ decrease with the increase of rotation speed. Vivek V. et al. [8] studied the effect of polygonal pin profiles on the superplasticity of FSPed AA7075 alloy. They suggested that evenly distributed hardness was found in the SZ on account of less pulsating actions and adequate material flow generated around the square pin. It was revealed by Somayeh et al. [9] that the size of insoluble particles in the SZ was markedly decreased with the 
variety of tool rotation speed, while smaller soluble based particles exhibited significant reduction in number only at higher tool rotation speeds due to severe plastic strain. Khaled J. et al. [10] documented the evolution of microstructures and mechanical properties produced with multi-pass FSP and concluded that all FSPed samples show a reduction in the tensile strength in comparison with the BM sample due to the dissolution of fine precipitates and reduction of dislocation density. Furthermore, the schemes of rapid cooling are successively adopted to suppress the excessive growth of grains after dynamic recrystallization (DRX) arise from the massive friction heat produced by the FSP [11]. The results demonstrated that FSP with rapid cooling method can efficiently refine the grain structures and achieve enhanced mechanical properties.

However, previous researches have heavily centered on the effect of FSP on microstructures and mechanical properties of SZ through adjusting the processing parameters except the initial precipitation state. And FSP were often performed on the BM under different single initial precipitation state, such as as-cast [12], as-deformed [10, 13, 14], annealed O-temper [15] and peak aged state [16]. The FSPed samples have an improvement in the tensile properties in comparison with the as-cast BM [12]. A detailed investigation on the microstructures and hardness of rolled pure aluminum was also carried out by Gan et al. [13]. They stated that the fine, equiaxed and recrystallized grains were observed in the SZ, and a "U"-shaped hardness curve was presented because of the local material softening occurred in the SZ induced by thermal cycle. Chen et al. [15] considered that multi-pass FSP was a feasible processing technique to fabricate fine-grained 7B04-O Al alloy and the grain size was irrespective of the moving distance. Moreover, the average grain size of SZ for aluminum alloy 2219-T6 was much smaller than that of the BM and the hardness was lower due to the transformation of meta-stable precipitates $\theta^{\prime}$ to equilibrium precipitates $\theta$ [7]. Accordingly, different initial precipitation states can change the type, size, and distribution of the particles in the SZ. These changes can decisively control the mechanical behaviors of alloy. However, the effects of different original precipitation states of $\mathrm{BM}$ on the microstructures and properties during FSP were not 
systematically proposed and lack of lateral comparison between them $[4,17,18]$. In view of the preceding discussion, the present work is to probe the important aspects of microstructures and microtexture evolution of the 2A14 aluminum alloy during FSP. The alloys were friction stir processed with different initial precipitation states (as-cast, homogenization, rolling and T6 state), and the consequent evolution of microstructures and mechanical properties and its mutual relation were explored in detail.

\section{Experimental procedure}

The 2A14 aluminum alloy plates selected for present study were received as as-cast, homogenized, hot-rolled and T6 states $(220 \mathrm{~mm}$ length, $60 \mathrm{~mm}$ width and 6 $\mathrm{mm}$ thick), respectively. The chemical composition of the alloy is $4.53 \% \mathrm{Cu}-0.46 \%$ $\mathrm{Mg}-0.88 \% \mathrm{Mn}-0.96 \% \mathrm{Si}-0.08 \% \mathrm{Fe}-0.02 \% \mathrm{Ti}$ (wt $\%$ ). Three different treatment processes (homogenization, hot rolling and T6) are applied accordingly for 2A14 alloy plates before FSP. The homogenization treatment of alloy plates was conducted at $490{ }^{\circ} \mathrm{C}$ for $10 \mathrm{~h}$. After that, the rolling process involved a combination of deformation temperature of $430{ }^{\circ} \mathrm{C}$ and total deformation of $60 \%$ with three processing passes was performed. Then the plates were T6 treatment comprised of solution treatment in a vacuum furnace at $505{ }^{\circ} \mathrm{C}$ for $3.5 \mathrm{~h}$ followed by water quenching at $21{ }^{\circ} \mathrm{C}$ within $10 \mathrm{~s}$ and subsequent aging treatment at $165{ }^{\circ} \mathrm{C}$ for $6 \mathrm{~h}$. Single pass FSP were performed with FSW-LM-BM16 welding machine at a constant linear speed of $120 \mathrm{~mm} / \mathrm{min}$ and a constant rotational speed of $1000 \mathrm{rpm}$ along the length direction of plate. A hot die steel stirring tool consisted of a scrolled shoulder with a diameter of $15 \mathrm{~mm}$ and a righthand threaded conical stirring pin with bottom diameter, top diameter and length of $6 \mathrm{~mm}, 4 \mathrm{~mm}$ and $5 \mathrm{~mm}$, respectively, was used to process sample. The tool plunge depth was varied between $0.1 \sim 0.3 \mathrm{~mm}$ while a tilt

angle (angle between spindle and workpiece normal) of $2.5^{\circ}$ was utilized. Concrete information about the processing equipment and geometry of the tool are given in Fig. 1.

The specimens for microstructure characterization and mechanical properties testing were cut with EDM in the stirred zones. The examined samples were ground 
and polished using standard metallographic procedures. And the Keller reagent was used for etching the samples to obtain an optical macrograph and microstructure. The cross-section microstructures were characterized by ZEISS Axio Imager $\mathrm{M}_{2} \mathrm{~m}$ optical microscope $(\mathrm{OM})$ and ZEISS Sigma 500 scanning electron microscope (SEM) equipped with energy dispersive spectroscopy (EDS). EBSD technique available in the same SEM was also used for evaluating detailed microstructure and microtexture evolution with the step size of $0.2 \sim 0.8 \mu \mathrm{m}$. The EBSD samples prepared via electro-polishing method on a Struers Lectropol-5 device using the standard A2 electrolyte. After that, the EBSD data analysis and post-processing were conducted with Oxford EBSD facility equipped with HKL-Channel 5 software. The transmission electron microscopy (TEM) was also used for investigating the distribution of precipitations and substructures by using a TECNAI G 20 TEM operated at $200 \mathrm{KV}$.

The Vickers hardness data were taken along the horizontal centerline of specimen's cross section by applying a load of $0.1 \mathrm{~kg}$ with a dwell time of $15 \mathrm{~s}$ on a HVS-1000A Vickers microhardness tester at $0.4 \mathrm{~mm}$ distance between successive indentations. Planar dog-bone tensile samples with $14 \mathrm{~mm}$ long $\times 4 \mathrm{~mm}$ wide $\times 1.8$ mm thickness gage dimensions were EDM along the processing direction only including the processed zone for all FSPed samples. The sampling locations of characterized samples and dimensions of the tensile specimens are indicated in Fig. 2. The room temperature tensile tests were performed on a computer-controlled CMT-5105 electronic universal testing machine operating at a constant crosshead speed of $1.0 \mathrm{~mm} / \mathrm{min}$. After testing, the final length of failed specimens was measured to determine the ductility.

\section{Results and discussion}

\subsection{Microstructure of the base alloy}

Fig. 3 shows the SEM images of 2A14 aluminum alloy base metal under different initial precipitation states. Fig. 3(a) exhibits classical cast microstructure, with a large amount of coarse residual eutectics distributed at the grain boundaries and a small quantity of second phases distributed at the grain boundaries and in the grain interiors. The coarse and uneven grains with the average grain size of 
around $143 \mu \mathrm{m}$ are observed. As shown in Fig. 3(b), although no apparent change in the grain size was found, the primary dendritic structures were effectively eliminated, numerous non-equilibrium eutectics distributed along the grain boundaries were dissolved into the matrix sufficiently and a few residual second phases were still retained at the grain boundaries after homogenization treatment. During the rolling process, the elongated microstructure is that of a typical hot-rolled plate with most of the grains were broken and refined, and rendered as fibrous along the rolling direction. The nonuniform grains are approximately $20 \sim 40 \mu \mathrm{m}$ along normal direction (ND) with the refined second phase particles are also displayed in Fig. 3(c). Moreover, Fig. 3(d) presents that the observed microstructure contains elongated-shaped grains and a large number of second phase particles after T6 treatment for hot-rolled sheet.

\subsection{Macrostructure}

The OM images of the cross-section in the SZ for the samples processed with different initial precipitation states are indicated in Fig. 4. Fig. 4(a) 4(d) show that the macroscopic morphologies of SZ produced with different precipitation states are similar. Namely the SZ are divided into: base metal (BM), heat affected zone (HAZ), thermal mechanical affected zone (TMAZ) and stirred zone (SZ). The basin-like SZ with relatively homogeneous etching contrast has a markedly broadening towards the upper region and the dimensions of SZ are proportional to the tool shape and size. The alternate distribution of fine and coarse grains were displayed in the upper region of SZ, while the bottom region shows incomplete onion-ring structure. It is revealed that the typical onion-ring structure can be correlated to the precipitation response and crystallographic texture in some of the FSPed aluminum alloys [19, 20]. Furthermore, the two sides of the centerline of SZ are asymmetrical, and the boundary slope between the SZ and TMAZ is larger in the AS than that of the RS, which is related to the existence of $2.5^{\circ}$ back tilt of the tool, resulting in different material flow on both sides. Additionally, a quite sharp interface was also revealed in the AS compared with the RS because of the larger gradients of strain and temperature in the AS [21].

\subsection{Microstructural evolution}

\subsubsection{Microstructure of the $S Z$}


The typical cross-section microstructures of SZ for the sample prepared with homogenized state are indicated in Fig. 5. The HAZ, which was only influenced by severe thermal cycling, was presented with coarse grains without any evident variety in the grain size. Next to the HAZ, a narrow transition region known as the TMAZ characterized by elongated and distorted grain structures was formed. On the one hand, the insufficient plastic deformation occurred in few grains of the TMAZ is believed to be the reason for dynamic recovery and DRX due to rotational friction and shear deformation of the stirring tool. It is obvious that the grain size in the TMAZ is larger than that of SZ, but much smaller than that of the BM due to the weakened stirring effect. Moreover, the TMAZ presents remarkably elongated microstructures along the rotating direction of tool arise from the effect of temperature gradient and strain rate. The grain structures with uneven deformation in the TMAZ are mainly caused by the shear force produced by the rotation of stirring tool, which have different effects on the grains with different orientations. The results of shear fracture within the microstructures are different, which results in the nonuniform grain size after DRX. Additionally, the finer, uniform and recrystallized microstructure with the average grain size of $3.1 \mu \mathrm{m}$ was observed in the SZ, which should be ascribed to the severe plastic deformation occurred in distinct strain rate and high temperature under the action of friction heat and mechanical stirring $[22,23]$.

\subsubsection{Grain structure and EDS results}

Fig. 6 shows the microstructures of SZ processed with different initial precipitation states. It is clear that all the SZ were defect free and no significant impact of the initial precipitation states of the BM on the grain size of SZ were noticed. Compared with the initial coarse grains of the BM under different precipitation states, the SZ experienced severe plastic deformation and produced fine equiaxed recrystallized grains under the heat-mechanical joint action during FSP. Consequently, a significant grain refinement to an average grain size of about $3.9 \mu \mathrm{m}$, $3.1 \mu \mathrm{m}, 4.2 \mu \mathrm{m}$ and $3.4 \mu \mathrm{m}$ were attained through FSP for the samples processed with as-cast, homogenization, rolling and T6 state, respectively. The homogeneity of microstructures in the SZ was improved and the grains were highly refined relative to 
the corresponding BM, which was ascribed to the occurrence of DRX during FSP as reported by Orozco-Caballero et al. and Chen et al. [4, 18]. Additionally, FSP result in significant fragmentation of the second particles and thus improve the dispersion homogeneity of particles. The EDS results of the particles denoted by arrows A and B in Fig. 6 are shown in Fig. 7. According to the high concentration of elements $\mathrm{Al}$ and $\mathrm{Cu}$ in the particles of $\mathrm{A}$, it is determined that these fine white particles are the $\theta$ $\left(\mathrm{Al}_{2} \mathrm{Cu}\right)$ phase. It is also worth noting that the fine $\mathrm{Al}_{2} \mathrm{Cu}$ intermetallics with high volume fraction are distributed within the structures. In addition, the denoted particles as point $\mathrm{B}$ are the dispersed inclusions rich in $\mathrm{Cu}, \mathrm{Fe}$ and $\mathrm{Mn}\left(\mathrm{Al}_{7} \mathrm{Cu}_{2}(\mathrm{Fe}, \mathrm{Mn})\right)$.

\subsubsection{Grain orientation and grain boundary character distribution}

The grain orientation and grain boundary character distribution of the BM and $\mathrm{SZ}$ are shown in Fig. 8. The color code in the selected regions corresponds to the grain orientation and the upper right corner represent the corresponding fraction of high angle boundaries (HAGBs, misorientation angle $>15^{\circ}$ ). Fig. 8 indicates that no obvious preferential orientations were presented in the BM and SZ. It was found that the BM (Fig. 8(a) 8(c)) exhibit coarse or elongated grains with a great quantity of low angle grain boundaries (LAGBs, misorientation angle of $3^{\circ} \sim 15^{\circ}$ ) for the as-cast, homogenized and rolled samples, respectively. After FSP, the BM with coarse or elongated grains were effectively modified and replaced by fine equiaxed grains. The substantial significant grain refinement is primarily due to serious plastic deformation and high temperature thermal exposure during FSP, which results in the creation of dynamic recrystallization. Some researchers [24] proposed that the geometric DRX (GDRX) can preferably explain the present work. The mechanism indicates that shear type deformation occurred in the grains during FSP, which makes the BM with coarse or elongated grains divide into fine equiaxed grains, as displayed in Fig. 8(a') 8(d').

Fig. $8\left(\mathrm{a}^{\prime}\right) \sim 8\left(\mathrm{~d}^{\prime}\right)$ illustrates that the SZ have fine equiaxed grain structures with high fraction of HAGBs, and sub-grains of LAGBs are also presented in the SZ after FSP. The results showed that there are no sharp distinctions in the volume fraction of HAGBs in the SZ regardless of the initial precipitation state. The SZ processed by T6 state has a relatively high volume fraction of HAGBs (89.5\%), while the SZ under the 
other initial precipitation states have similar grain boundary characteristics $(81.4 \%$, $80.5 \%$ and $78.3 \%$, respectively). Moreover, the fraction of HAGBs in the SZ are obviously higher than that of the corresponding BM, which has a HAGBs fraction of $56.3 \%, 57.1 \%, 30.8 \%$ and $64.2 \%$, respectively, for the $\mathrm{BM}$ under as-cast, homogenized, rolled and T6 state. Additionally, the variation in the grain size can be neglected for the SZ fabricated with different initial precipitation states, which indicating that the initial states does not bring significant function to the grain boundary characteristic and grain size.

\subsubsection{TEM observation}

Fig. 9 displays TEM images of the BM under different initial precipitation states and the corresponding SZ. As seen from Fig. 9 (a) and 9(b), low density linear dislocation distribution were presented in $\alpha$ (Al) matrix under as-cast and homogenized state. Huge amount of dislocations are also created in Fig. 9 (c) due to the severe plastic strain caused by rolling process. Unlike the rolled BM, there is tiny amounts of dislocations are observed and the $\theta / \theta^{\prime}$ phases with the size of about 200 $\mathrm{nm}$ are dispersed uniformly throughout the $\mathrm{Al}$ matrix for the BM under T6 state, as shown in Fig. 9 (d).

Fig. 9(a') $\sim 9$ (d') reveals the influences of different initial precipitation states on the microstructural evolution of the SZ. It can be observed from Fig. 9(a') 9(d') that the SZ processed with homogenized state BM has the highest volume fraction of dispersions, followed by the T6, as-cast and rolled state after FSP. The homogeneous distributed precipitated phases, composed mainly by $\mathrm{Al}_{2} \mathrm{Cu}$ and ranging in size from $100-300 \mathrm{~nm}$, are responsible for the excellent precipitation hardening behavior of 2A14 Al alloy, as shown in Fig. 9(b'). Fig. 9(a') and 9(b') exhibit that the size of most precipitates in the SZ is about $200 \mathrm{~nm}$, while the size of precipitates inside grains increases slightly after FSP, as shown in Fig. 9(c') and 9(d'). Generally, the FSPed sample showed higher density of phases due to the breakup of micron-sized phases

during FSP compared with the respective BM and the size of dispersions is slightly larger in the rolled state than that of the other three initial precipitation states. Additionally, it is worth mentioning that FSP can also result in the annihilation of 
dislocation lines, as described in Fig. 9(a'), 9(b') and 9(c').

\subsection{Microtexture evolution}

Fig. 10 depicts the $\{111\}$ pole figures of the BM and SZ center produced by different initial precipitation states. Fig. 10(a) and 10(b) give the microtexture of the $\mathrm{BM}$ under as-cast and homogenized state, demonstrating that the microtexture of BM is mainly composed of $\{001\}<110>$ Rotated Cube. The predominant microtexture components obtained after hot-rolling process in Fig. 10(c) can be characterized as $\{001\}<100>$ Cube and incomplete fiber $(<110>/ /$ rolling direction). Besides, the main recrystallization textures consisting of $\{011\}<100>$ Goss, $\{001\}<100>$ Cube and $\{124\}<211>\mathrm{R}$ were developed in the BM sample under T6 state, as shown in Fig. 10(d). After FSP, the prevailing deformation mode is simple shear although the material flow is very complicated $[25,26]$. Comparing the $\{111\}$ pole figures of the $\mathrm{BM}$ and $\mathrm{SZ}$ center, it is obvious that changing the initial precipitation states of $\mathrm{BM}$ does not have any influences on the texture components evolved in the SZ. Experimental results showed that the fine grain structures with shear texture components of $\mathrm{C}$ and $\mathrm{A}_{1} *$ can be achieved through the GDRX mechanism. Almost the same shear texture components are generated in the SZ and the texture intensities are less under the above four precipitation conditions. It indicates that the contribution of additional grain refinement mechanism of discontinuous DRX (DDRX) may be involved, which is conducive to forming randomly oriented grains [26, 27].

\subsection{Mechanical properties}

\subsubsection{Hardness distributions}

Fig. 11 depicts microhardness distribution map in the cross-section of SZ for the FSPed 2A14 aluminum alloy plates fabricated with different initial precipitation states. As shown in Fig. 11, significant enhancement can be obtained in the hardness of SZ for the samples prepared by as-cast and homogenized states compared with the corresponding BM, while the FSPed samples processed by rolled and T6 states BM showed the reduction in the hardness despite huge grain refinement. With regard to the BM, the hardness value of T6 sample is the highest while that of as-cast sample is the lowest. It is noticed that the average hardness of the BM subjected to casting, 
homogenization, rolling and T6 process are measured $65.8 \mathrm{HV}, 84.1 \mathrm{HV}, 124.4 \mathrm{HV}$ and 155.9 $\mathrm{HV}$, respectively. When the FSP were performed on the as-cast and homogenized alloys, the maximum hardness value are about twice than that of the corresponding $\mathrm{BM}$ and decreased by $3.2 \%$ and $12.2 \%$ compared to the hardness of the unprocessed locations for the rolled and T6 states specimens. The maximum amount of hardness in the SZ is $155.4 \mathrm{HV}$ and was observed in the specimen produced by homogenized state BM.

\subsubsection{Tensile properties}

Fig. 12 shows the tensile properties of the FSPed samples and respective BM. The tensile strengths are in the range of $362.13 \sim 424.61 \mathrm{MPa}$ for the FSPed samples fabricated with different initial precipitation states, while it is approximately equal to 177.23 MPa, 246.7 MPa, 389 MPa and 431 MPa for the BM of as-cast, homogenized, rolled and T6 states samples, respectively. The tensile strength of FSPed samples prepared with rolled and T6 states demonstrated a decrease compared with the respective BM, while the FSPed samples exhibited improved tensile properties compared with the corresponding $\mathrm{BM}$ under as-cast and homogenized states. As depicted from Fig. 12, the highest ultimate tensile strength value (424.61MPa) was obtained in the SZ processed with homogenized BM among all processing states. Additionally, the elongation values also showed substantial changes related to initial precipitation state except for the differences in tensile strength. The elongation of SZ for the specimens fabricated with different initial states are about $8.05 \%, 11.17 \%$, $16.7 \%$ and $11.3 \%$, respectively, which is higher than that of the corresponding BM.

\section{Discussion}

The results obtained above confirmed that the change of mechanical properties of SZ for FSPed specimens depend strongly on the microstructural evolution, including grain size, second particles, precipitates and dislocation density [28]. According to the Hall-Petch equation, grain refinement can effectively strengthen the materials [29]. However, besides the fine grain strengthening, the mechanical properties are also determined by precipitation strengthening for the age-hardenable aluminum alloy $[18,30]$. The enhancement of yield strength contribution from 
precipitation strengthening can be evaluated using as follows [31]:

$$
\Delta \sigma=0.13 \mathrm{MG} \frac{\mathrm{b}}{2 \sqrt{\mathrm{rh}}}\left[f_{v^{2}}^{\frac{1}{2}}+0.75\left(\frac{r}{h}\right)^{\frac{1}{2}} f_{v}+0.14\left(\frac{r}{h}\right) f_{v^{\frac{3}{2}}}^{\frac{3}{2}}\right] \ln \left(\frac{0.158 r}{r_{0}}\right)
$$

Where $\Delta \sigma$ is the improvement of yield strength, $\mathrm{M}, \mathrm{G}, b, \mathrm{r}, \mathrm{h}$ and fv are the Taylor factor, shear modulus, Burgers vector, and the radius, thickness and volume fraction of precipitates, respectively, and $\mathrm{r}_{0}$ is the inner radius of dislocations around strengthening phases. From Eq. (1), it can be seen that the reduced size and increased number density of the precipitates are beneficial to obtain excellent yield strength. Meanwhile, the mechanical properties of SZ are also governed by the dislocation density as estimated using the Bailey-Hirsch relationship [29].

As seen from Fig. 12, the tensile strength and elongation of the BM were lower than the SZ for the FSPed samples fabricated with as-cast and homogenized states, which was sparked by several factors such as casting defects, grain size and the size and distribution of phases $[12,32]$. As to the as-cast $2 \mathrm{~A} 14 \mathrm{Al}$, the initial grains, insoluble eutectic phases and precipitates are coarse and thus it has lower tensile strength and elongation. Performing FSP led to markedly reduced grain size. It can be observed from Fig. 12 that the SZ has remarkably higher mechanical properties than the BM, which was related to the fine grained structures with predominant HAGBs induced by the DRX. At the SZ of FSPed sample, the dissolution of coarse precipitates was accelerated significantly and hard $\mathrm{Al}_{2} \mathrm{Cu}$ phases started to disappear due to severe plastic deformation at elevated temperature during FSP, as shown in Fig. 6 and Fig. 9.

With regard to homogenized sample, microstructure characteristics of the BM and SZ showed many privileges relative to the as-cast sample. First, the porosities and voids of the homogenized 2A14 Al alloy nearly completely disappeared after FSP, while minute quantities of voids were still presented in as-cast sample because the porosities, voids and $\mathrm{Al}_{2} \mathrm{Cu}$ phases of the as-cast $\mathrm{BM}$ can be effectively eliminated by homogenization treatment (see Fig. 3 and Fig. 6). Second, The SZ of homogenized sample had finer and more uniform microstructures relative to the as-cast sample after 
DRX. Third, more coarse particles in the grain boundaries were dissolved and the re-precipitated fine $\theta\left(\mathrm{Al}_{2} \mathrm{Cu}\right)$ phases with uniform volume distribution were presented during FSP for the FSPed sample performed with homogenized state BM. Since homogenized sample had finer and more uniform microstructures and the greater number of fine particles, and porosities, voids and hard $\mathrm{Al}_{2} \mathrm{Cu}$ phases were removed or at least were reduced through homogenization treatment, thus the SZ of homogenized sample has higher tensile strength and elongation compared with the SZ processed by as-cast BM. Similar research results have been reported by Liu et al. and Luo et al $[12,32]$, who proclaimed that the mechanical properties of SZ were improved after multi-pass FSP due to the uniform and fine grains and the elimination of casting defects.

Based on the previous studies $[10,13]$, the variations in the precipitates and dislocation density play a more serious role than the grain size with respect to influencing the mechanical properties of SZ during FSP. It is anticipated that the strengthening mechanism in the SZ are mainly determined by the grain size and the distribution of precipitates while the dislocation density is dominant for the BM under rolled state, as shown in Fig. 9. On the one hand, the slight softened SZ relative to the $\mathrm{BM}$ are observed for the rolled sample despite it has fine-grained structures $(4.2 \mu \mathrm{m})$ after FSP. The previous researches revealed that grain refinement has very limited contribution on the enhancement of the strength of FSPed samples [7]. As illustrated in Fig. 6 and Fig. 9, most of the particles were broken or dissolved and the fine precipitates $\theta\left(\theta^{\prime}\right)$ were partially dissolved or coarsened in the SZ during FSP. Subsequently, the particles or precipitates reformed and the remained phases became coarsened during the following cooling process. Furthermore, the results shown in Fig. 9 undoubtedly validated that the dislocation density of SZ is decreased significantly compared to the dislocation density in the BM sample, signifying that the DRX occurred in the SZ. Therefore, the strength and hardness of SZ prepared by rolled BM sample were slightly deteriorated due to the reduction of dislocation density and dissolution/coarsening of fine phase particles. 
Besides, significant reduction can be found in the strength and hardness of SZ compared with the BM under T6 state, as displayed in Fig. 11 and Fig. 12. It is demonstrated that the precipitate characteristics of SZ produced with different initial precipitation states play a striking role in adjusting the tensile properties [4, 18]. Before FSP, the initial strengthening precipitates of the T6 state BM were fine and numerous, thus the precipitation strengthening effect was relatively strong. After FSP, the precipitation strengthening decreased significantly due to the initial fine precipitates $\theta\left(\theta^{\prime}\right)$ disappeared and the remained precipitates $\theta\left(\theta^{\prime}\right)$ are further coarsened, as shown in Fig. 9. The difference in the size and distribution of precipitates indicated that the precipitates in the SZ are overaged due to the thermal cycle accumulation generated from the FSP, which give rise to the decrease in the mechanical properties of SZ [15]. Consequently, the SZ are softened for the BM under T6 state because the strength contributions arising from grain and second particles refinement cannot compensate for the strength reductions caused by precipitation strengthening and dislocation strengthening, which consistent with the microstructure features shown in Figs. 6-9. For this net effect, the SZ cannot achieve the strength of the precipitation strengthened T6 state BM sample. Additionally, the weakened strengthening effect due to the loss of coherent relationship between the precipitates and matrix after FSP could also explain the substantial reduction in the strength and hardness [7].

\section{Conclusions}

In present study, the microstructural evolution and mechanical properties of friction stir processed 2A14 aluminum alloy under different initial precipitation states were evaluated. The main conclusions derived from the experimental results were as follows:

(1) Performing FSP with air cooling were found to be beneficial for achieving fine equiaxed grain structures with a higher fraction of HAGBs in the range of $78.3 \%$ $\sim 89.5 \%$ for the BM under as-cast, homogenized, rolled and T6 states.

(2) Under the above four precipitation conditions, the recrystallized grains with random orientation were formed in the SZ. The initial texture components were 
removed, almost the same shear texture components of $\mathrm{C}$ and $\mathrm{A}_{1} *$ were generated and weakened texture intensities were also obtained in the SZ after FSP, which is ascribed to the combined effects of simple shear deformation, GDRX and DDRX.

(3) The SZ processed with homogenized state has the highest volume fraction of dispersions, followed by the T6, as-cast and rolled state after FSP. And the FSPed sample showed higher density of phases compared with the respective BM due to the breakup of micron-sized phases during FSP.

(4) The SZ processed by the BM under as-cast and homogenized states were significantly strengthened due to the obvious refined grain and more uniform microstructures, while the softened SZ were obtained for the BM under rolled and T6 states, where the softening effect of lower dislocation density and precipitates dissolution/coarsening overwhelm the strengthening effect of grain and second phase particles refinement.

\section{Compliance with ethical standards}

Competing interests The authors declare that they have no known competing financial interests or personal relationships that could have appeared to influence the work reported in this paper.

Acknowledgments The authors are grateful for the support from the Jiangsu University of Technology for providing the FSP equipment.

Funding This research was funded by the National Natural Science Foundation of China (No. 51701088), the Major Project of Education Department, Jiangsu Province (No. 18KJA43007) and Key Laboratory of Advanced Materials Design and Additive Manufacturing of Jiangsu Province in Jiangsu University of Technology.

Authors' contributions Conceptualization, data curation and writing original draft, J. Wang; formal analysis, methodology and investigation, K. Yang; project administration and visualization, D.S. Zhou; supervision and funding acquisition, L. Xie; software and supervision, Y.L Lu; resources, X.C Li.

\section{References}


1. Y.X. Zhang, Y.P. Yi, S.Q. Huang, F. Dong (2016) Influence of quenching cooling rate on residual stress and tensile properties of 2A14 aluminum alloy forgings. Mater Sci Eng A 674 658-665.

2. M. Wang, L.P. Huang, W.S. Liu, Y.Z. Ma, B.Y. Huang (2016) Influence of cumulative strain on microstructure and mechanical properties of multi-directional forged 2A14 aluminum alloy. Mater Sci Eng A 674: 40-51.

3. P.B. Berbon, W.H. Bingel, R.S. Mishra, C.C. Bampton, M.W. Mahoney (2001) Friction stir processing: a tool to homogenize nanocomposite aluminum alloys. Scr Mater 44: 61-66.

4. A. Orozco-Caballero, P. Hidalgo-Manrique, C.M. Cepeda-Jiménez, P. Rey, D. Verdera, O.A. Ruano, F. Carreño (2016) Strategy for severe friction stir processing to obtain acute grain refinement of an $\mathrm{Al}-\mathrm{Zn}-\mathrm{Mg}-\mathrm{Cu}$ alloy in three initial precipitation states. Mater Charact 112: 197-205.

5. A. Orozco-Caballero, C.M. Cepeda-Jiménez, P. Hidalgo-Manrique, P. Rey, D. Gesto, D. Verdera, O.A. Ruano, F. Carreño (2013) Lowering the temperature for high strain rate superplasticity in an $\mathrm{Al}-\mathrm{Mg}-\mathrm{Zn}-\mathrm{Cu}$ alloy via cooled friction stir processing. Mater Chem Phys 142: 182-185.

6. M.S. Khorrami, M. Kazeminezhad, Y. Miyashita, N. Saito, A.H. Kokabi (2017) Influence of ambient and cryogenic temperature on friction stir processing of severely deformed aluminum with SiC nanoparticles. J Alloys Comp 718: 361-372.

7. X.L. Feng, H.J. Liu, J.C. Lippold (2013) Microstructure characterization of the stir zone of submerged friction stir processed aluminum alloy 2219. Mater Charact 82: 97-102.

8. V.V. Patel, V. Badheka, A.Kumar (2017) Effect of polygonal pin profiles on friction stir processed superplasticity of AA7075 alloy. J Mater Process Technol 240: 68-76.

9. S. Pasebani, I. Charit, R.S. Mishra (2015) Effect of tool rotation rate on constituent particles in a friction stir processed 2024Al alloy. Mater Lett 160: 64-67.

10. K.J. Al-Fadhalah, A.I. Almazrouee, A.S. Aloraier (2014) Microstructure and mechanical properties of multi-pass friction stir processed aluminum alloy 6063. Mater Des 53: 550-560. 
11. W.F. Xu, J.H. Liu, D.L. Chen, G.H. Luan (2014) Low-cycle fatigue of a friction stir welded 2219-T62 aluminum alloy at different welding parameters and cooling conditions. Int J Adv Manuf Technol 74: 209-218.

12. F.C. Liu, Z.Y. Ma (2008) Effect of friction stir processing on the microstructure of as-cast 7075 aluminum alloy. Acta Metall Sin 44: 319-324 (in China).

13. W.Y. Gan, Z. Zhou, H. Zhang, T. Peng (2014) Evolution of microstructure and hardness of aluminum after friction stir processing. Trans Nonferrous Met Soc China 24: $975-981$.

14. L.B. Johanned, R.S. Mishra (2007) Multiple passes of friction stir processing for the creation of superplastic 7075 aluminum. Mater Sci Eng A 464: 255-260.

15. Y. Chen, H. Ding, S. Malopheyev, R. Kaibyshev, Z.H. Cai, W.J. Yang (2017) Influence of multi-pass friction stir processing on microstructure and mechanical properties of 7B04-O Al alloy. Trans Nonferrous Met Soc China 27: 789-796.

16. M.M. El-Rayes, E.A. El-Danaf (2012) The influence of multi-pass friction stir processing on the microstructure and mechanical properties of aluminum alloy $6082 . \mathrm{J}$ Mater Process Technol 212: 1157-1168.

17. S. Malopheyev, V. Kulitskiy, S. Mironov, D. Zhemchuzhnikova, R. Kaibyshev (2014) Friction stir welding of an Al-Mg-Sc-Zr alloy in as-fabricated and work-hardened conditions. Mater Sci Eng A 600: 159-170.

18. Y. Chen, H. Ding, Z.H. Cai, J.W. Zhao, J.Z. Li (2016) Effect of initial base metal temper on microstructure and mechanical properties of friction stir processed Al-7B04 alloy. Mater Sci Eng A 650: 396-403.

19. N. Nadammal, S.V. Kailas, J. Szpunar, S. Suwas (2015) Microstructure and crystallographic texture evolution during the friction-stir processing of a precipitation hardenable aluminum alloy. JOM 67: 1014-1021.

20. Y. Tao, Z. Zhang, D.R. Ni, D. Wang, B.L. Xiao, Z.Y. Ma (2014) Influence of welding parameter on mechanical properties and fracture behavior of friction stir welded Al-Mg-Sc joints. Mater Sci Eng A 612: 236-245.

21. R. Nandan, T. Debroy, H.K.D.H. Bhadeshia (2008) Recent advances in friction-stir welding-Process, weldment structure and properties. Prog Mater Sci 53: 
980-1023.

22. D. Yadav, R. Bauri (2011) Processing, microstructure and mechanical properties of nickel particles embedded aluminum matrix composite. Mater Sci Eng A 528: $1326-1333$.

23. T.R. Mcnelley, S. Swaminathan, J.Q. Su (2008) Recrystallization mechanisms during friction stir welding/processing of aluminum alloys. Scr. Mater. 58: 349-354. 24. R.S. Mishra, Z.Y. Ma (2005) Friction stir welding and processing. Mater Sci Eng R 50: 1-78.

25. R.W. Fonda, J.F. Bingert, K.J. Colligan (2004) Development of grain structure during friction stir welding. Scr Mater 51: 243-248.

26. P.B. Prangnell, C.P. Heason (2005) Grain structure formation during friction stir welding observed by the 'stop action technique'. Acta Mater 53: 3179-3192.

27. X.L. Feng, H.J. Liu, S.S. Babu (2011) Effect of grain size refinement and precipitation reactions on strengthening in friction stir processed $\mathrm{Al}-\mathrm{Cu}$ alloys. Scr Mater 65: 1057-1060.

28. H.J. Zhang, M. Wang, X. Zhang, G.X. Yang (2015) Microstructural characteristics and mechanical properties of bobbin tool friction stir welded 2A14-T6 aluminum alloy. Mater Des 65: 559-566.

29. G.E. Dieter, Mechanical Metallurgy, 3rd ed., McGraw-Hill, New York, 1986.

30. Y. Chen, H. Ding, J.Z. Li, J.W. Zhao, M.J. Fu, X.H. Li (2015) Effect of welding heat input and post-welded heat treatment on hardness of stir zone for friction stir-welded 2024-T3 aluminum alloy. Trans Nonferrous Met Soc China 25: 2524-2532.

31. A.W. Zhu, E.A. Starke (1999) Strengthening effect of unshearable particles of finite size: a computer experimental study. Acta Mater 47: 3263-3269.

32. X.C. Luo, D.T. Zhang, W.W. Zhang, C. Qiu, D.L. Chen (2018) Tensile properties of AZ61 magnesium alloy produced by multi-pass friction stir processing: Effect of sample orientation. Mater Sci Eng A 725: 398-405. 


\section{Caption of Figures}

Fig. 1 The sketches of experimental equipment and stirring tool: (a) Experimental layout and (b) Stirring tool

Fig. 2 Scheme of extraction of characterization specimen

Fig. 3 SEM images of the base metal under different initial states: (a) As-cast, (b) Homogenization, (c) Rolled and (d) T6

Fig. 4 Macrograph of transversal cross-section of FSP samples produced by the base metal under (a) As-cast, (b) Homogenization, (c) Rolled and (d) T6

Fig. 5 The microstructures of SZ processed by homogenized BM from various areas of (a)(d) TMAZ of RS, (b) SZ and (c)(e) TMAZ of AS

Fig. 6 SEM images of the SZ produced by the base metal under (a) As-cast, (b) Homogenization, (c) Rolled, (d) T6

Fig. 7 EDS results of second phase particles in the SZ: (a) Point A and (b) Point B Fig. 8 Grain orientation and grain boundary character distribution maps of the BM and SZ under different initial precipitation states: Before FSP (a) As-cast, (b) Homogenization, (c) Rolled, (d) T6, After FSP (a') As-cast, (b') Homogenization, (c') Rolled and (d') T6

Fig. 9 TEM micrographs of the BM and SZ under different initial precipitation states: Before FSP (a) As-cast, (b) Homogenization, (c) Rolled, (d) T6, After FSP (a') As-cast, (b') Homogenization, (c') Rolled and (d') T6

Fig. $10\{111\}$ pole figures of 2A14 alloy specimens measured in the BM under (a) As-cast, (b) Homogenization, (c) Rolled and (d) T6, and the SZ produced by different initial precipitation states under (e) As-cast, (f) Homogenization, (g) Rolled and (h) T6

Fig. 11 Microardness distribution maps across the cross-section of SZ under different initial precipitation states

Fig. 12 Tensile properties of SZ produced with different initial precipitation states 


\section{Figures}
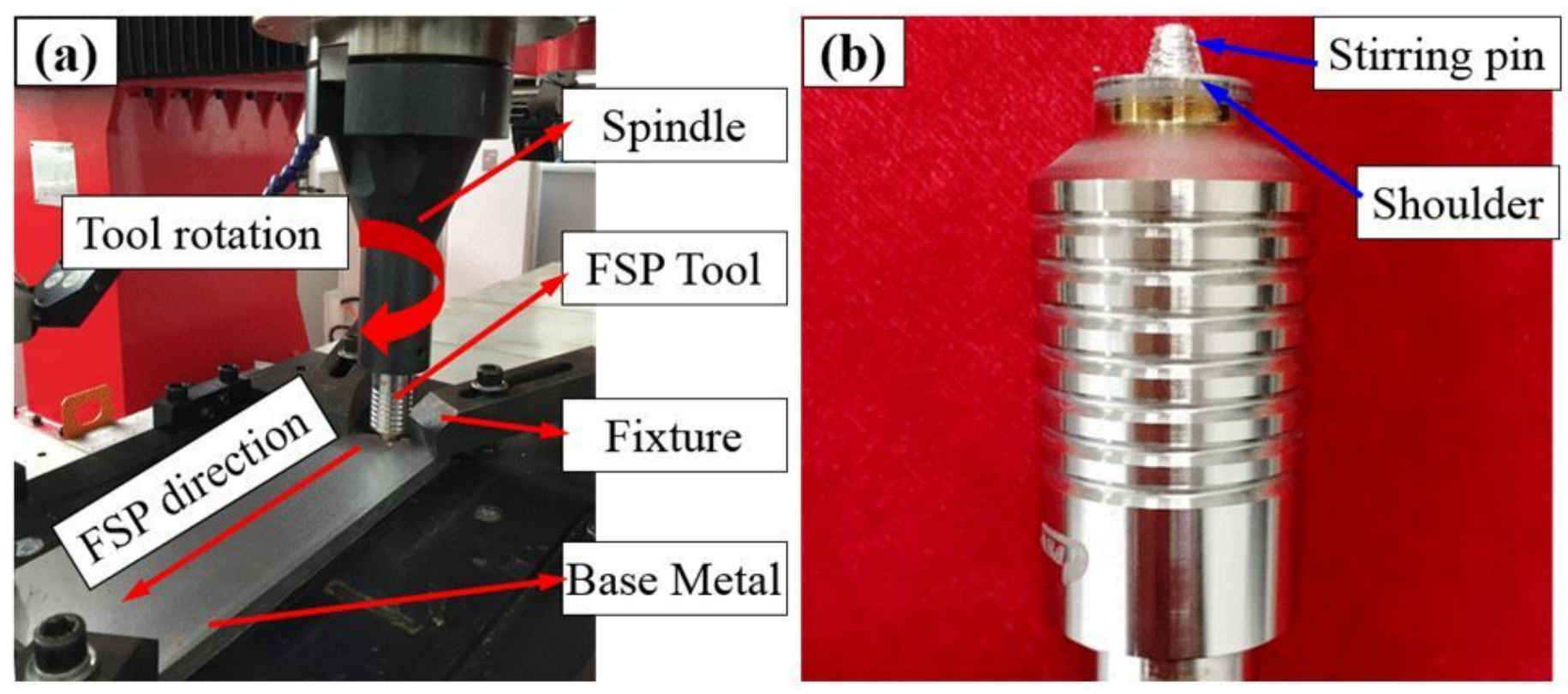

Figure 1

The sketches of experimental equipment and stirring tool: (a) Experimental layout and (b) Stirring tool

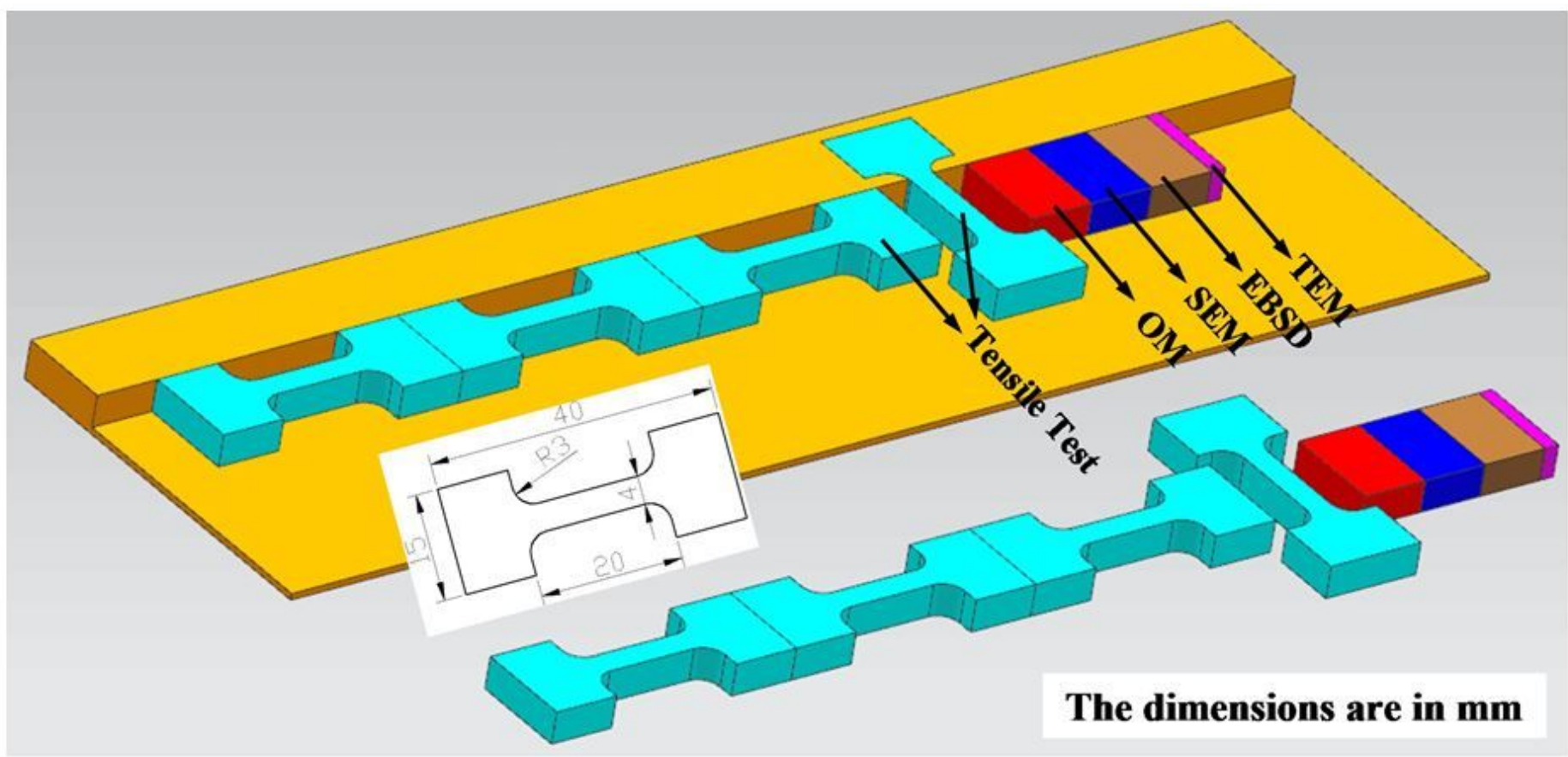

Figure 2

Scheme of extraction of characterization specimen 

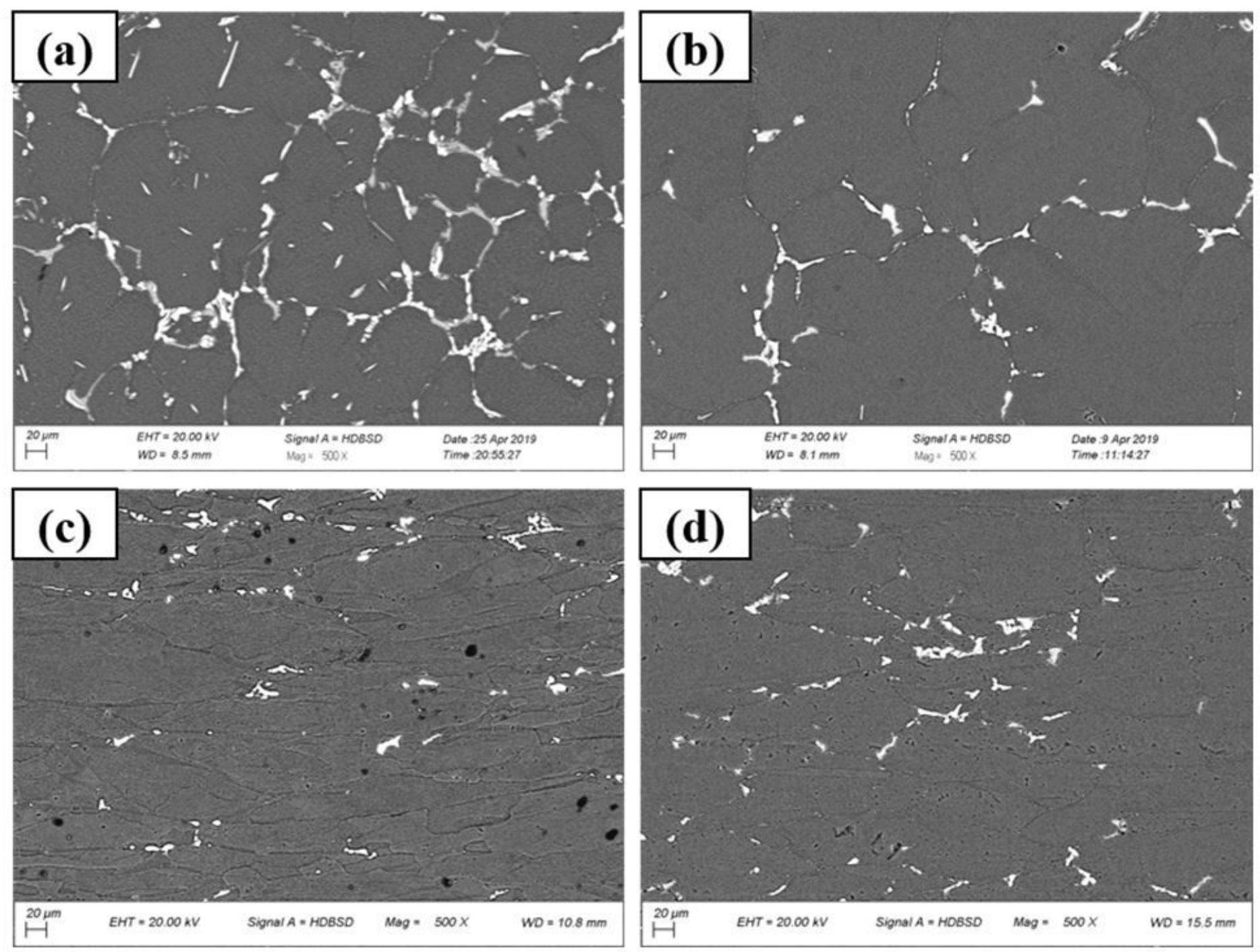

Figure 3

SEM images of the base metal under different initial states: (a) As-cast, (b) Homogenization, (c) Rolled and (d) T6 

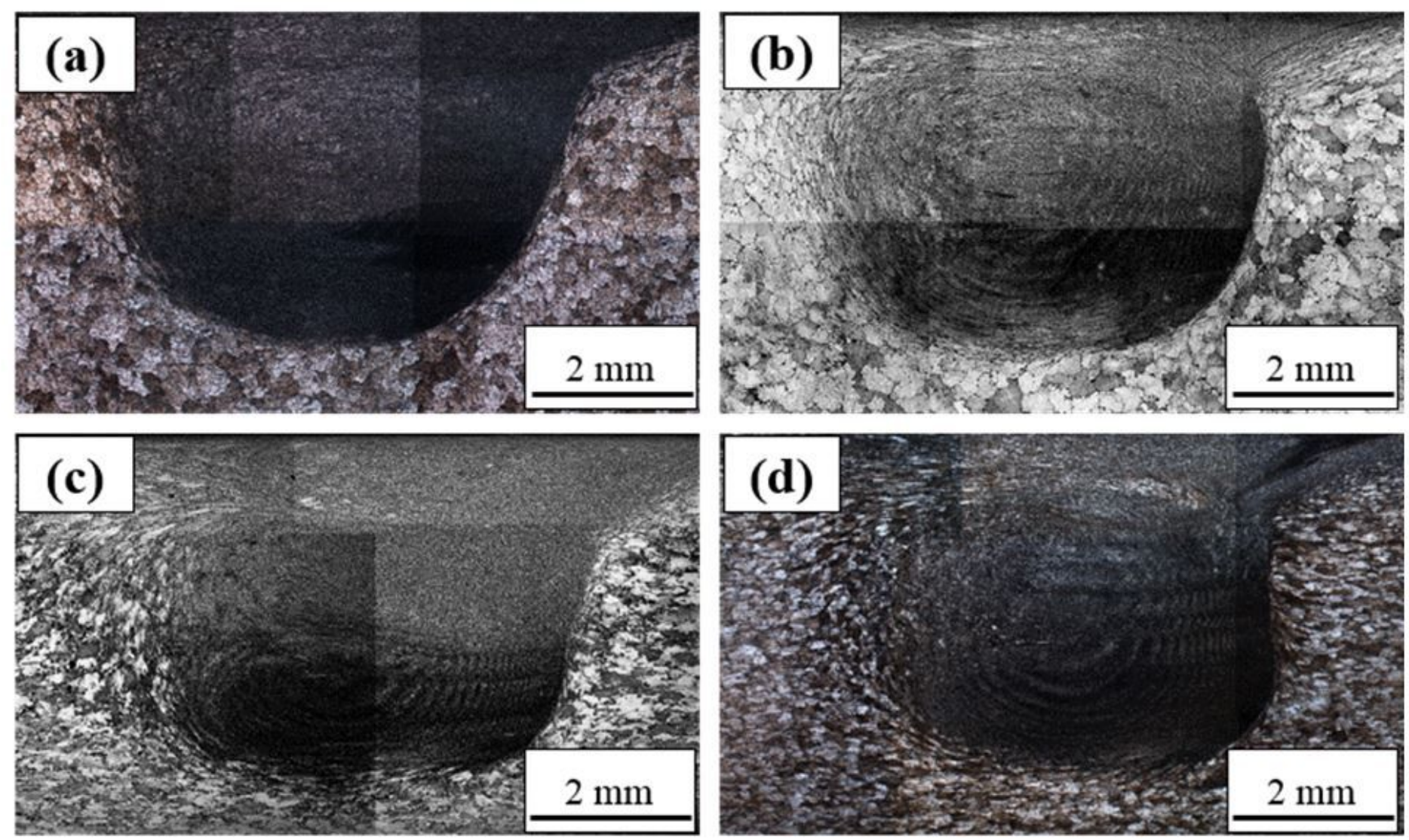

Figure 4

Macrograph of transversal cross-section of FSP samples produced by the base metal under (a) As-cast, (b) Homogenization, (c) Rolled and (d) T6
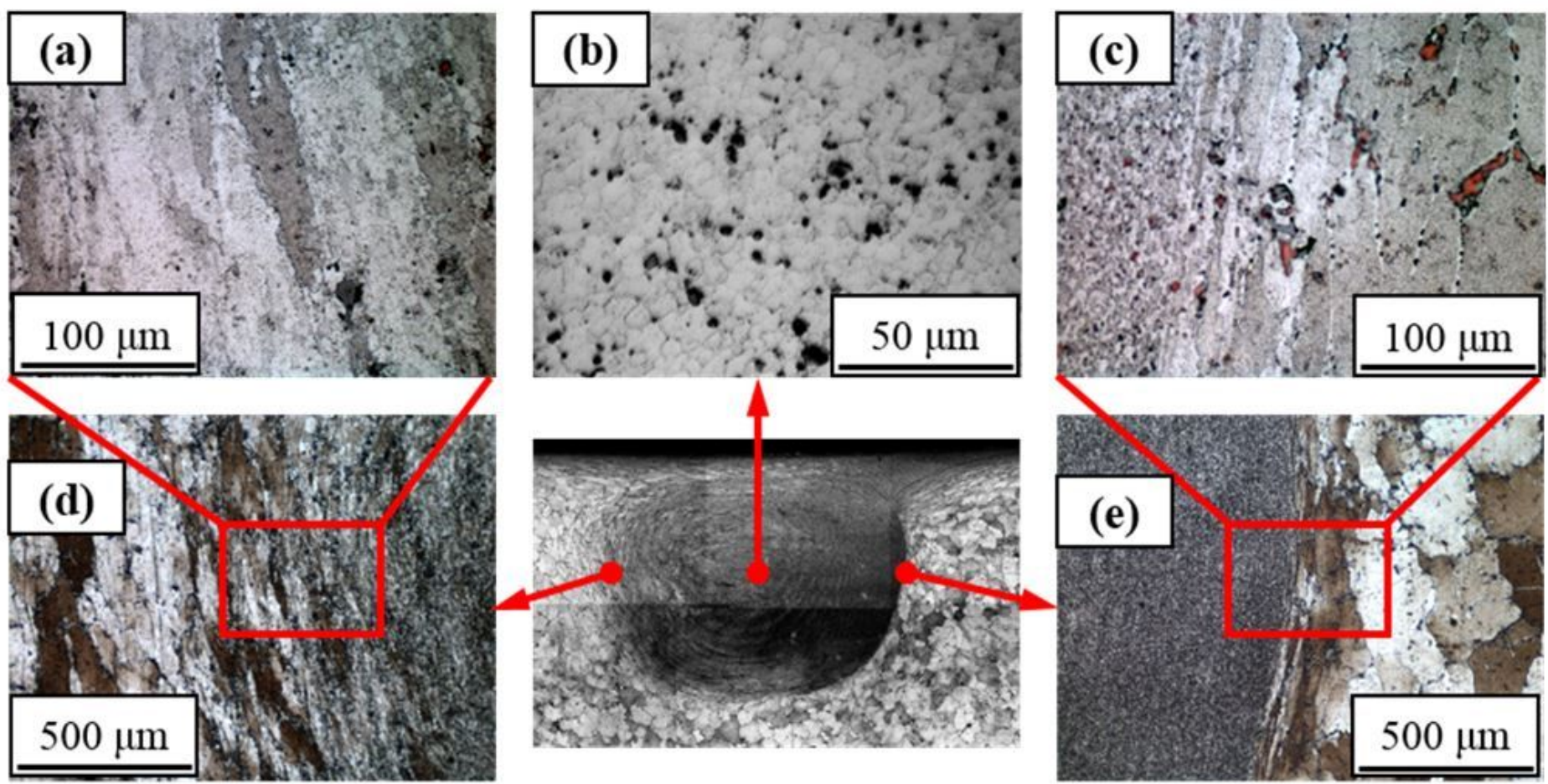


\section{Figure 5}

The microstructures of SZ processed by homogenized BM from various areas of (a)(d) TMAZ of RS, (b) SZ and (c)(e) TMAZ of AS
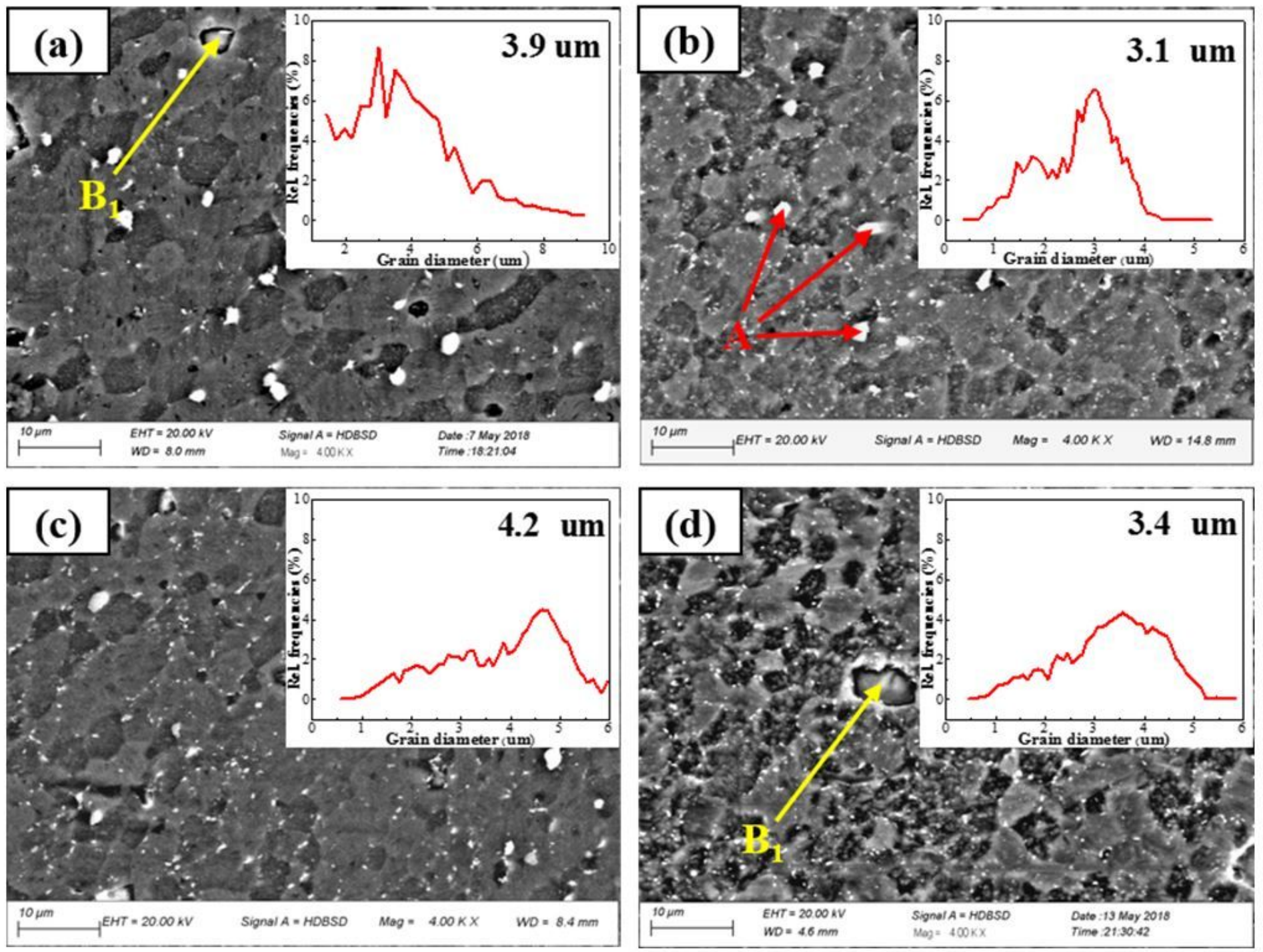

Figure 6

SEM images of the SZ produced by the base metal under (a) As-cast, (b) Homogenization, (c) Rolled, (d) T6 

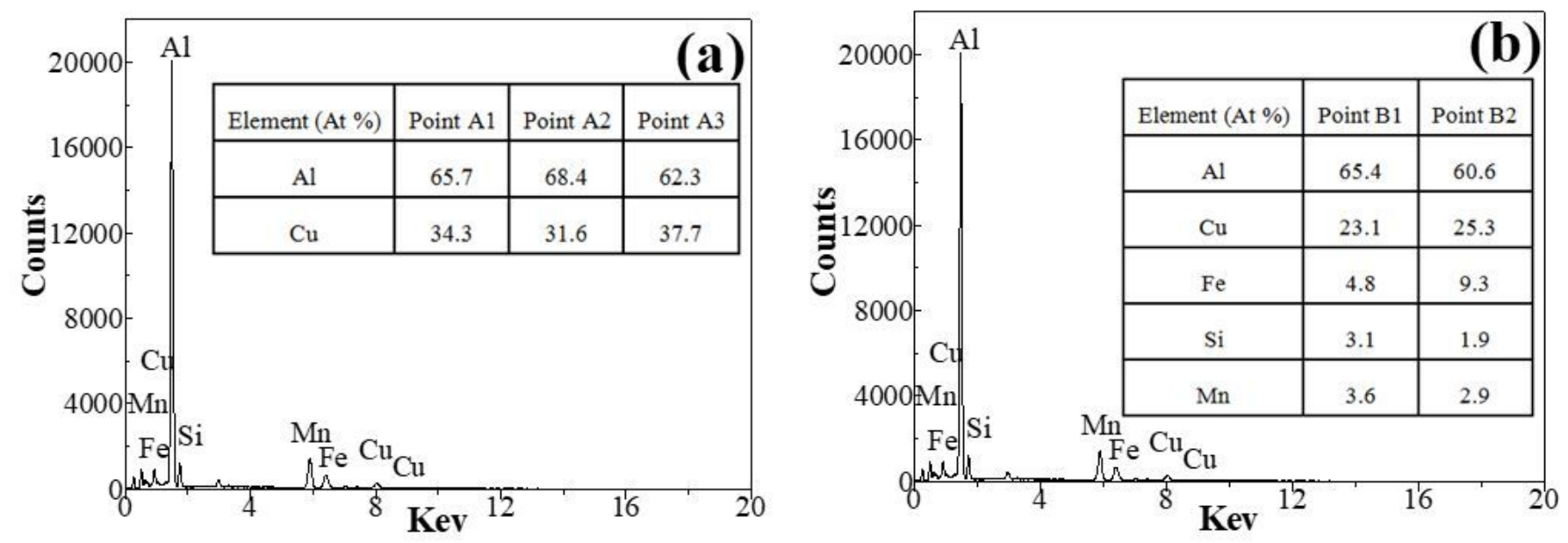

Figure 7

EDS results of second phase particles in the SZ: (a) Point A and (b) Point B
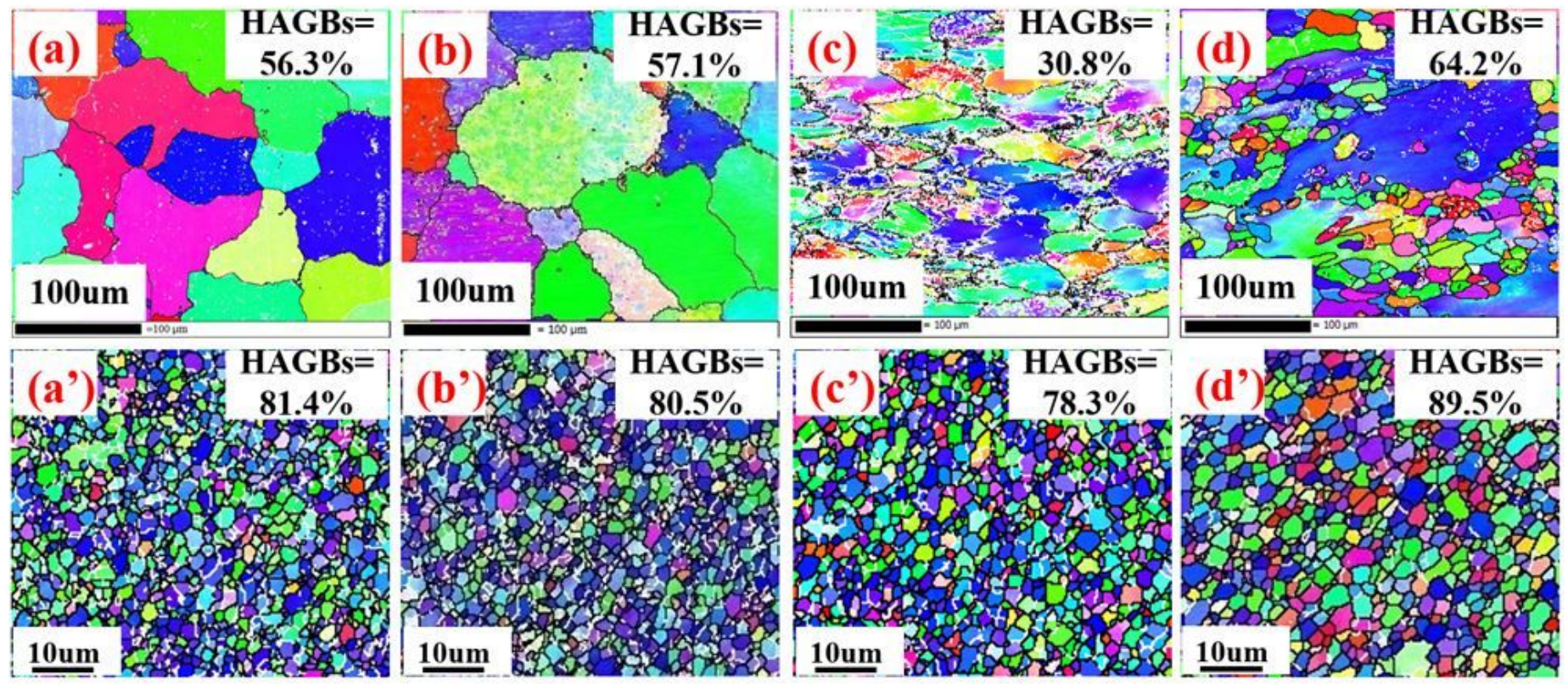

Figure 8

Grain orientation and grain boundary character distribution maps of the BM and SZ under different initial precipitation states: Before FSP (a) As-cast, (b) Homogenization, (c) Rolled, (d) T6, After FSP (a') As-cast, (b') Homogenization, (c') Rolled and (d') T6 

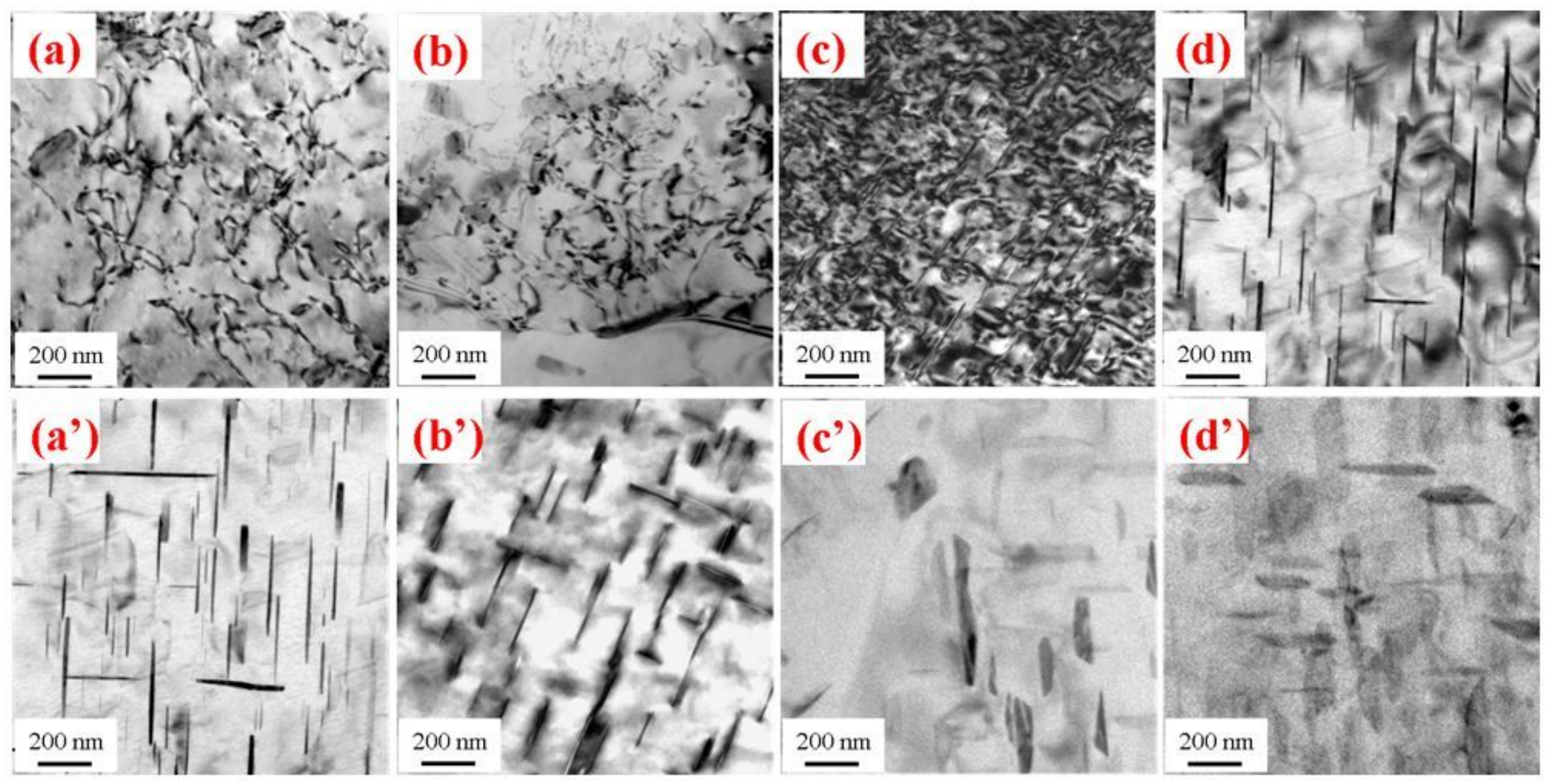

\section{Figure 9}

TEM micrographs of the BM and SZ under different initial precipitation states: Before FSP (a) As-cast, (b) Homogenization, (c) Rolled, (d) T6, After FSP (a') As-cast, (b') Homogenization, (c') Rolled and (d') T6
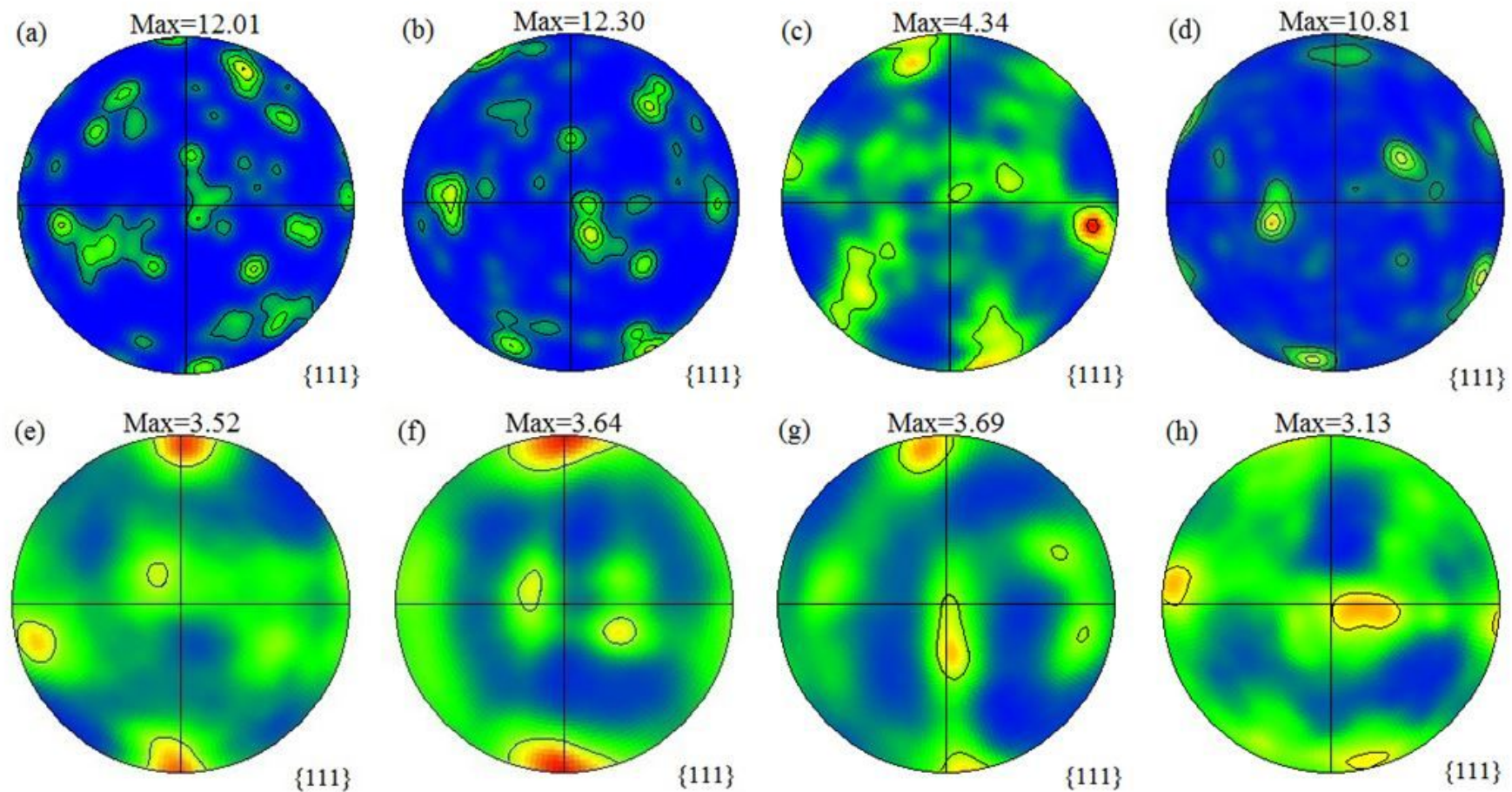

Figure 10 
$\{111\}$ pole figures of 2A14 alloy specimens measured in the BM under (a) As-cast, (b) Homogenization, (c) Rolled and (d) T6, and the SZ produced by different initial precipitation states under (e) As-cast, (f) Homogenization, (g) Rolled and (h) T6

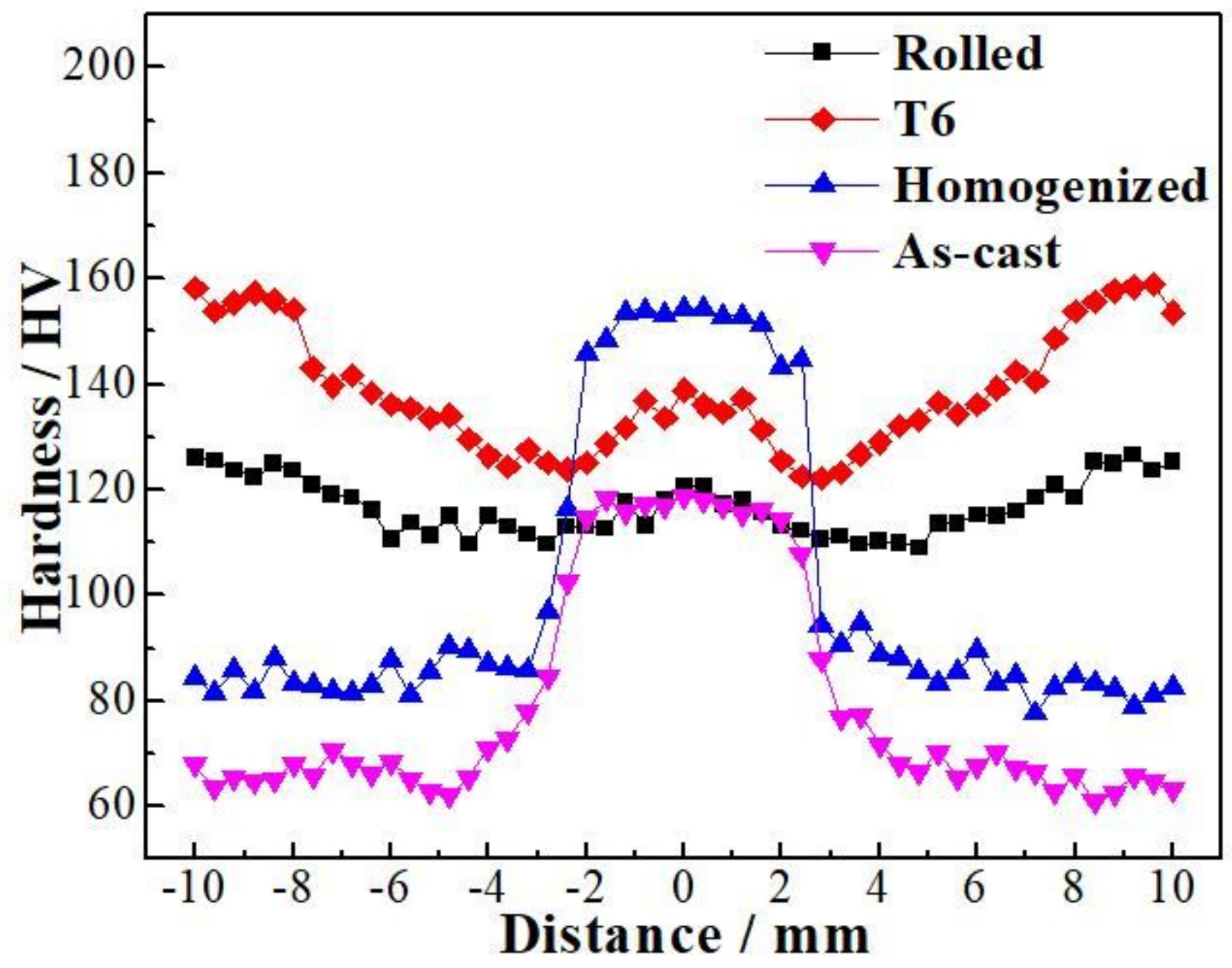

Figure 11

Microardness distribution maps across the cross-section of SZ under different initial precipitation states 

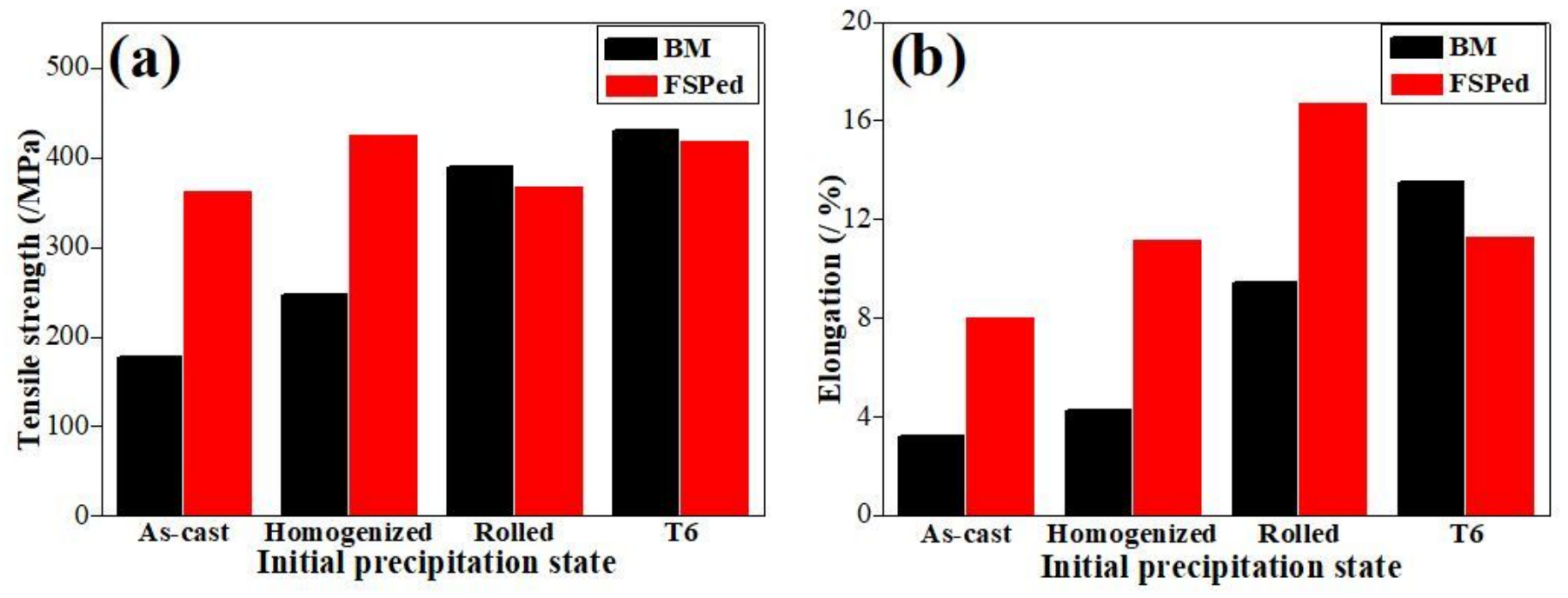

Figure 12

Tensile properties of SZ produced with different initial precipitation states 